\title{
Surface Topography and Mixed-Pixel Effects on the Simulated L-Band Brightness Temperatures
}

\author{
Marco Talone, Student Member, IEEE, Adriano Camps, Senior Member, IEEE, \\ Alessandra Monerris, Student Member, IEEE, Mercè Vall-llossera, Member, IEEE, \\ Paolo Ferrazzoli, Member, IEEE, and María Piles, Student Member, IEEE
}

\begin{abstract}
The impact of topography and mixed pixels on L-band radiometric observations over land needs to be quantified to improve the accuracy of soil moisture retrievals. For this purpose, a series of simulations has been performed with an improved version of the Soil Moisture and Ocean Salinity (SMOS) End-to-End Performance Simulator (SEPS). The brightness temperature $\left(T_{\mathrm{B}}\right)$ generator of SEPS has been modified to include a 100-m-resolution land cover map and a 30-m-resolution digital elevation map of Catalonia (northeast of Spain). This highresolution $T_{\mathrm{B}}$ generator allows the assessment of the errors in soil moisture retrieval algorithms due to limited spatial resolution and provides a basis for the development of pixel disaggregation techniques. Variation of the local incidence angle, shadowing, and atmospheric effects (up- and downwelling radiation) due to surface topography has been analyzed. Results are compared to brightness temperatures that are computed under the assumption of an ellipsoidal Earth.
\end{abstract}

Index Terms-L-band radiometry, mixed pixel, simulator, SMOS End-to-End Performance Simulator (SEPS), Soil Moisture and Ocean Salinity (SMOS), topography.

\section{INTRODUCTION}

$\mathbf{T}$ HE AVAILABILITY of high-resolution brightness temperature $\left(T_{\mathrm{B}}\right)$ maps at L-band is crucial to analyze important issues dealing with bare and vegetation-covered land emission and to develop inversion algorithms in preparation for real Soil Moisture and Ocean Salinity (SMOS) mission data. Mixed-pixel, coastlines, shadowing, and topography effects on the measured brightness temperatures need further study, but the lack of global geophysical data at sufficient temporal and spatial resolution and the large amount of data involved in the generation of high-resolution $T_{\mathrm{B}}$ maps on a global basis complicate the issue. In fact, in spite of the existence of global digital elevation models with sufficient spatial resolution, accurate land cover data do not exist for most parts of the world.

To address these issues, a series of simulations has been performed with an improved version of the SMOS End-to-End Performance Simulator (SEPS) [1], [2], in which, to date, all points on Earth have been assumed to be at sea level. The study

Manuscript received May 30, 2006; revised February 14, 2007. This study has been supported by the CICYT under Project TEC2005-06863-C02-01.

M. Talone, A. Camps, A. Monerris, M. Vall-llossera, and M. Piles are with the Remote Sensing Laboratory, Department Teoria del Senyal i Comunicacions, Universitat Politècnica de Catalunya, 08034 Barcelona, Spain.

P. Ferrazzoli is with Tor Vergata University, Ingegneria, DISP, 00133 Roma, Italy.

Color versions of one or more of the figures in this paper are available online at http://ieeexplore.iee.org.

Digital Object Identifier 10.1109/TGRS.2007.898254 has been done over the region of Catalonia, on the northeastern coast of Spain, because of its many different land cover types, topography, and the presence of a coastline. A 30-m-resolution digital elevation map [3] and a 100-m-resolution land coverage map of Catalonia [4] have been used as inputs, and SEPS has been conveniently modified to generate high-resolution $T_{\mathrm{B}}$ maps of this area. A variety of soil and land cover types (crops, bushes, marshes, etc.) have been parameterized using the values obtained from field experiments and literature [5]-[10], [12].

\section{Generation of High-Resolution BRightness TEMPERATURE MAPS AT L-BAND}

\section{A. Description of the Auxiliary Data}

A digital elevation model [3] and a land cover map [4] of Catalonia (northeast Spain; Fig. 1) have been used as inputs to the high-resolution $T_{\mathrm{B}}$ generator. The digital elevation model of Catalonia (DEMC) has $30 \times 30 \mathrm{~m}$ resolution and is referred to the official reference system European Datum 1950. Real and estimated values from 4957 test points were compared, and a root mean-square error (RMSE) of $2.6 \mathrm{~m}$ for the first version and $1.4 \mathrm{~m}$ for the second version were obtained. The first version of DEMC is available for the whole region, whereas the second version (with a lower RMSE) is available only for two thirds of Catalonia. The DEMC was used to account for the effect of topography and shadowing on the radiometric signal. On the other hand, the land coverage map of Catalonia [Mapa de Cobertes del Sòl de Catalunya (MCSC), Fig. 1] has 100-m resolution and includes 21 different land cover types. In the latest version, these categories are divided into subcategories, which better characterize the environment, but this finer classification is only available for one third of Catalonia. The classification follows the legend proposed by the European Environmental Agency, CORINE, but with a 50 times better resolution.

High-resolution $T_{\mathrm{B}}$ maps are generated combining the DEMC and the MCSC information and are composed of an area with the top left corner at $\left(42^{\circ} 55^{\prime} \mathrm{N}, 0^{\circ} 8^{\prime} \mathrm{E}\right)$ and with the bottom right corner at $\left(40^{\circ} 28^{\prime} \mathrm{N}, 3^{\circ} 25^{\prime} \mathrm{E}\right)$.

\section{B. Brightness Temperature Maps Generator: Input Parameters}

By taking into account the auxiliary data, a local incidence angle at each DEMC $30 \times 30 \mathrm{~m}$ pixel has been computed, and a set of geophysical parameters has been associated with each category of the MCSC. The geophysical parameters 


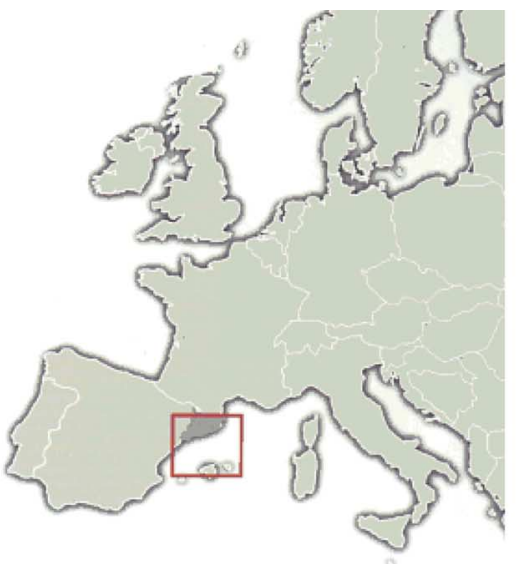

(a)
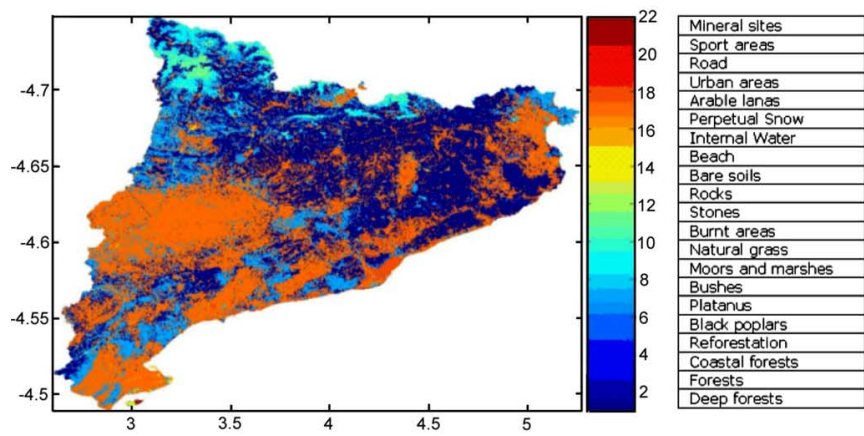

(b)

Fig. 1. (a) Region of Catalonia is located in the northeast of Spain. (b) Land cover map of Catalonia, divided into 21 categories and with 100-m resolution.

TABLE I

SEPS Simulation VAlues FOR EACH SoIl AND Vegetation PARAMETER (SA/CL: SOIL SAND/Clay FraCtions [10]; P: SOIL POROSITY)

\begin{tabular}{l|ccccccc}
\hline Land cover category & $\sigma_{S}(\mathrm{~mm})$ & $A$ & $B$ & $\mathrm{VWC}\left(\mathrm{Kg} / \mathrm{m}^{2}\right)$ & $\mathrm{SA}(\%)$ & $\mathrm{CL}(\%)$ & $\mathrm{P}(\%)$ \\
\hline \hline Deep forests [5] [7] & 6 & $10^{-3}$ & 0.1 & 6 & 78 & 2 & 50 \\
Forests [5]-[7] & 6 & $10^{-3}$ & 0.1 & 4 & 78 & 2 & 50 \\
Coastal forests [5]-[7] & 6 & $10^{-3}$ & 0.1 & 4 & 78 & 2 & 50 \\
Reforestation [5]-[7] & 6 & $10^{-3}$ & 0.1 & 2 & 78 & 2 & 50 \\
Black poplars [5]-[7] & 6 & $10^{-3}$ & 0.1 & 4 & 78 & 2 & 50 \\
Platanus [5]-[7] & 6 & $10^{-3}$ & 0.1 & 4 & 78 & 2 & 50 \\
Bushes [5];[8];[9] & 6 & 0 & 0.04 & 0.3 & 67 & 15 & 30 \\
Moors and marshes [5];[8];[9] & 6 & 0 & 0.04 & 0.7 & 67 & 15 & 30 \\
Burnt areas [5];[6];[7] & 6 & $10^{-3}$ & 0.1 & 2 & 85 & 2 & 30 \\
Rice fields [5] & 80 & & & & 0 & 0 & 50 \\
Natural grass [5];[8];[9] & 20 & & & & 0 & 0 & 50 \\
Bare soils [5] & 6 & & & & 85 & 2 & 30 \\
Beach [5] & 0 & & & & 90 & 0 & 40 \\
Arable lands [5] & 24 & $1.8 \mathrm{e}^{-3}$ & -0.01 & 1.5 & 21 & 36 & 30 \\
Urban areas [5];[11] & 0 & & & & & & \\
Roads [5];[11] & 0 & & & & & & \\
Sport areas [5];[11] & 0 & & & & & & \\
Mineral sites [5] & 80 & & & & & & \\
\end{tabular}

considered for an accurate description of each pixel are those most commonly used in the literature: the albedo $\omega$, which is considered to be linearly dependent on the incidence angle $(\omega=$ $A \cdot \theta(\mathrm{deg})+B$, with $A$ and $B$ obtained by linear regression of the values in $[8$, Table 1]), the vegetation water content (VWC), which affects the opacity $(\tau)$, the soil roughness $\sigma$, the texture (percentage of sand, silt, and clay), and porosity $P$. The values of each parameter for each land cover type are listed in Table I. The albedo and the VWC values for forests have been

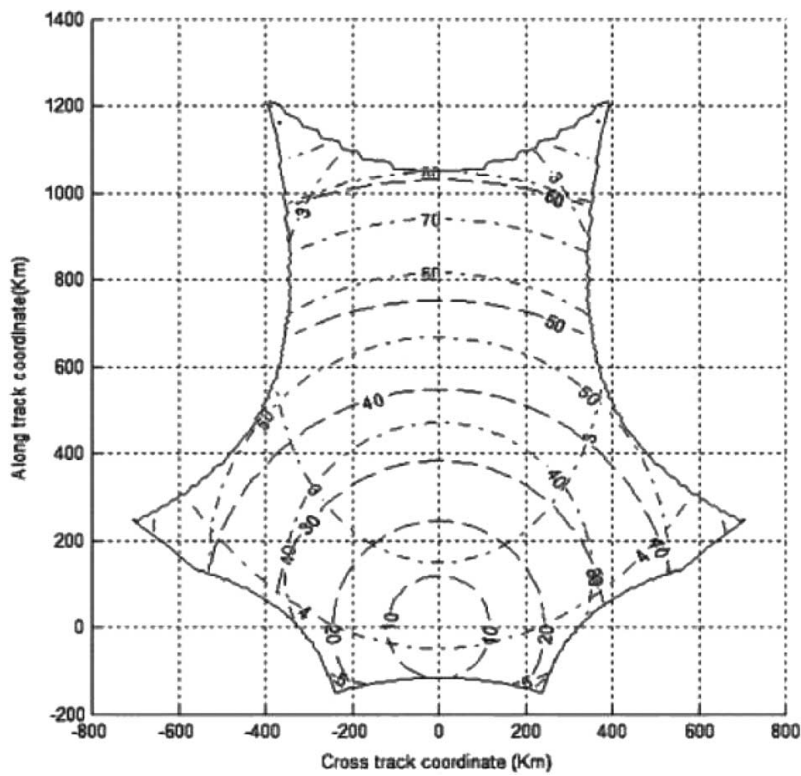

Fig. 2. SMOS instantaneous alias-free FOV (irregular curved hexagon) illustrates the multiangular and spatially variable nature of the measurements. The incidence angle (dashed lines) ranges from $0^{\circ}$ to $65^{\circ}$, and the spatial resolution (dash-dot lines) from 40 to $80 \mathrm{~km}$

obtained from the studies in [6] and [7], and those for bushes have been obtained from the studies in [8] and [9]. Whenever possible, soil texture and roughness values have been obtained from measurements acquired during the MOUSE 2004 and T-REX 2004 field experiments [10] and [11], and typical values for each soil type have been considered for the porosity. Urban areas have been characterized according to the study in [12]. Due to the VWC data availability for most of the land cover types, the opacity has been computed as $\tau=b \cdot \mathrm{VWC}$, where $b$ is a vegetation structure parameter, dependent on vegetation type, frequency, and polarization. At a frequency of $1.4 \mathrm{GHz}, b$ is supposed to be equal to 0.15 at both polarizations [13].

\section{SEPS Simulator RESUlTS}

\section{A. Introduction}

To better understand the simulation results presented in the next sections, the three coordinate systems used in SMOS analysis must be described. The first one is referred to the local pixel on the Earth, and in this case, the horizontal and the vertical polarizations are called $H$ and $V$. In the second one, which is referred to the antenna plane, the polarizations are called $X$ and $Y$. At boresight, $X$ and $Y$ are identical to $H$ and $V$ polarizations, respectively, but away from boresight, there is some polarization mixing [14]. The third coordinate system $(\xi, \eta)$ is also referred to the antenna, but in the direction cosine domain with respect to $X$ and $Y:(\xi, \eta)=(\sin \theta \cos \phi, \sin \theta \sin \phi)$. The instrument topology and observation geometry are described in [1, Fig. 1]. All the figures presented in this paper are referred to the antenna plane and represented in the direction cosine domain.

The SMOS instantaneous alias-free field of view (FOV) is shown in Fig. 2. SMOS has multiangular observation 

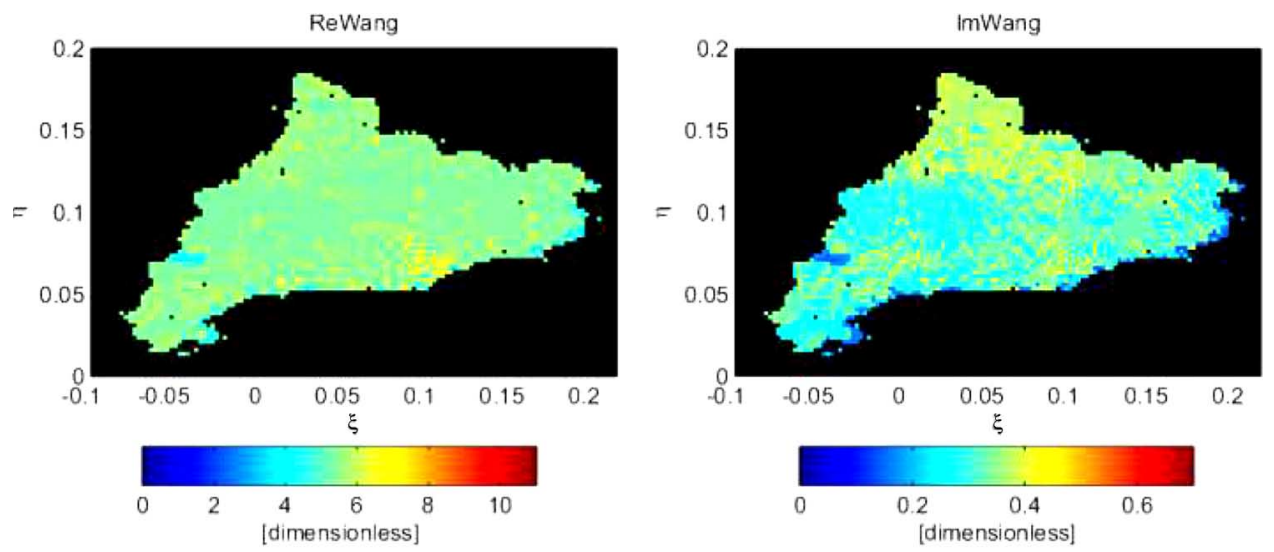

(a)
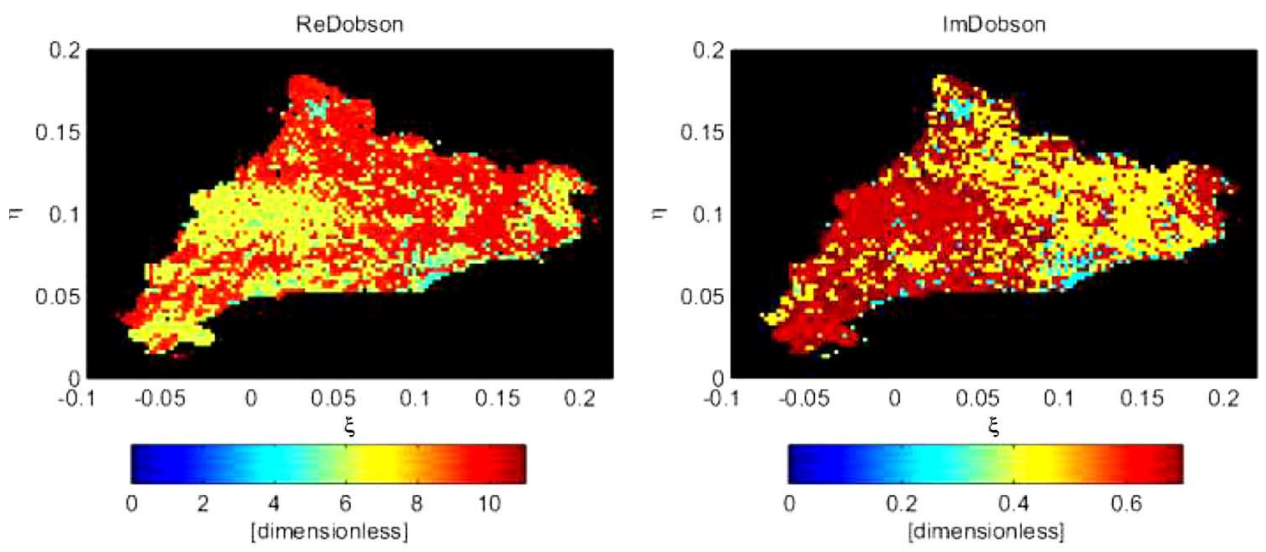

(b)

Fig. 3. (a) Real (left) and imaginary (right) parts of the soil dielectric constant using the semiempirical model in [15]. (b) Real (left) and imaginary (right) parts of the soil dielectric constant using the semiempirical model in [16]. The direction $\operatorname{cosines}(\xi, \eta)$ are defined as $(\sin \theta \cos \phi$, $\sin \theta \sin \phi)$, respectively.
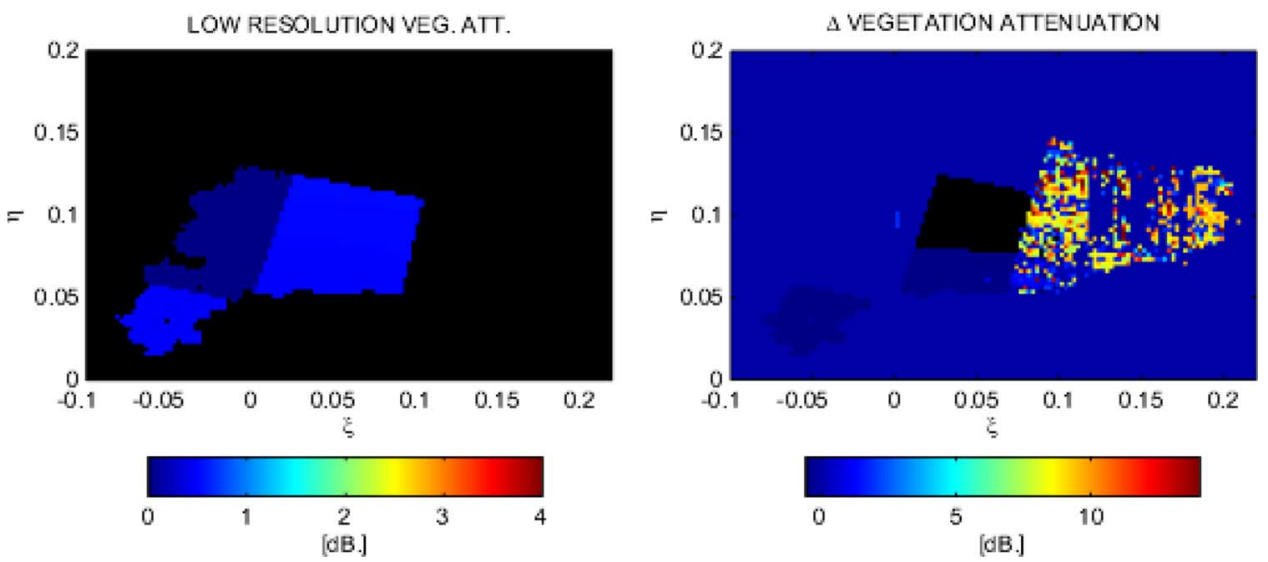

Fig. 4. (Left) Attenuation due to vegetation for the low-esolution map. (Right) Difference between the vegetation attenuation in the high- and low-resolution brightness temperature maps.

capabilities. The incidence angle (dashed lines) ranges from $0^{\circ}$ to about $65^{\circ}$; the spatial resolution (dash-dot lines) ranges from less than 40 to $80 \mathrm{~km}$, with best spatial resolution of $32 \mathrm{~km}$; and the radiometric sensitivity (dash-dot) ranges from about $2.4 \mathrm{~K}$ at boresight to $5 \mathrm{~K}$. As the satellite advances, a single spot is seen in successive snapshots from different incidence angles, and the spatial and radiometric resolutions depend on its position within the instrument FOV. These capabilities of SMOS are expected to improve the retrieval of geophysical parameters.

\section{B. Dielectric Constant of Soils}

By using the land cover map of Catalonia and the texture values in Table I, the dielectric constant $\varepsilon_{\mathrm{S}}$ of soils has been simulated. The soil water content value was the same as the one used in the prior version of SEPS so that the variations due to the different dielectric constant models could be analyzed. Simulation results for the semiempirical $\varepsilon_{S}$ models of Wang and Schmugge [15] and Dobson et al. [16] are shown in Fig. 3(a) and (b), respectively. Different values are observed, depending 

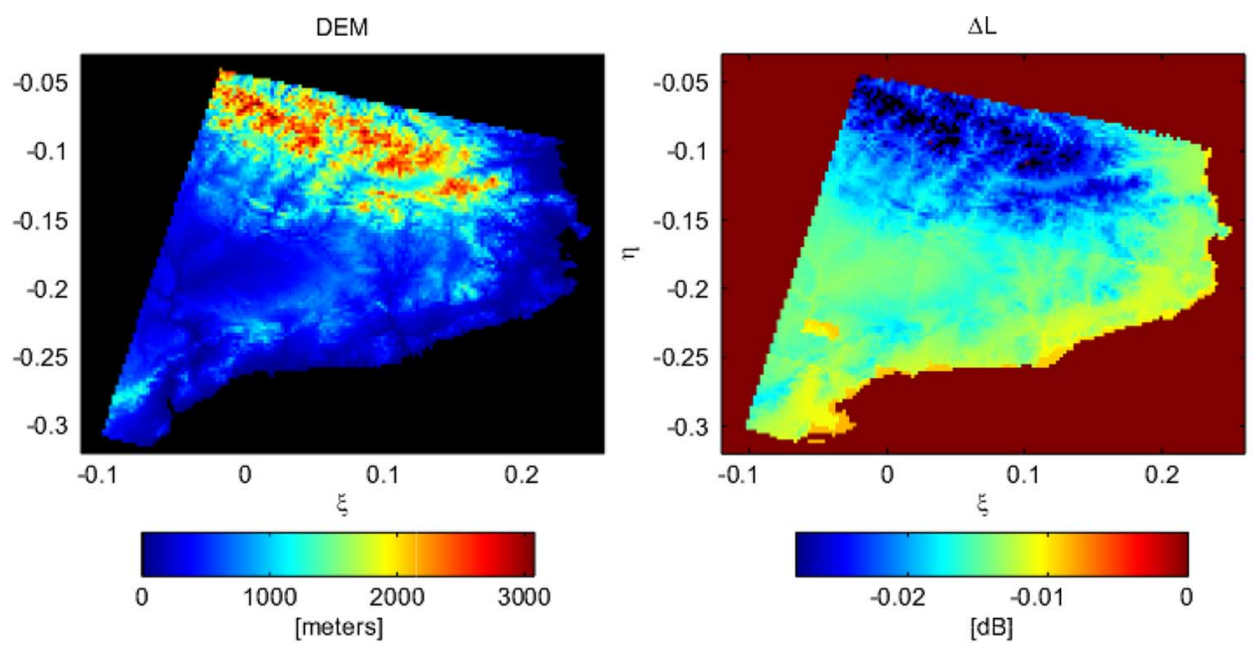

(a)
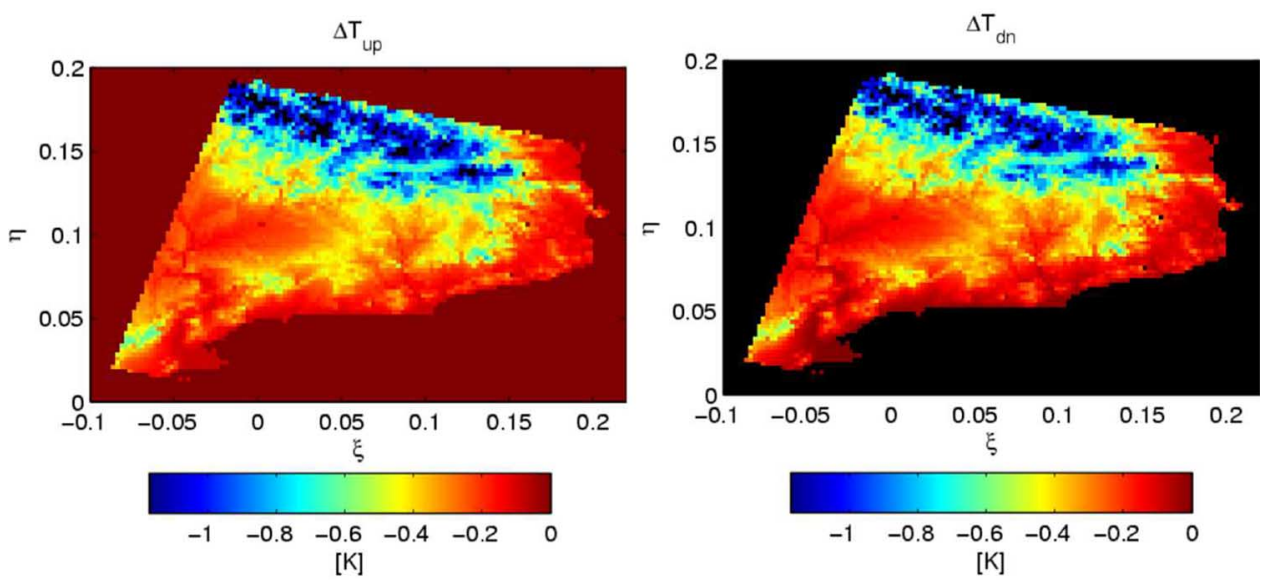

(b)

Fig. 5. (a) Variation of the atmospheric attenuation due to pixel height $\left(\Delta L_{\mathrm{atm}}=L_{\mathrm{atm}}\left[\right.\right.$ considering DEMC] $-L_{\mathrm{atm}}$ [ellipsoidal Earth]). (b) Variation of the up- and downwelling atmospheric temperatures due to height $\left(\Delta T_{\mathrm{up} / \mathrm{dn}}=T_{\mathrm{up} / \mathrm{dn}}[\right.$ considering DEMC $]-T_{\mathrm{up} / \mathrm{dn}}$ [ellipsoidal Earth] $)$.

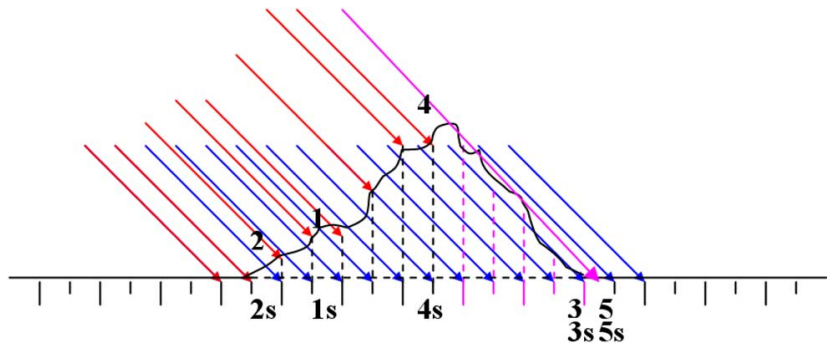

Fig. 6. Effects of topography. Blue lines correspond to satellite-to-pixel vectors when the land is supposed to be ellipsoidal (and, thus, all the points are visible). Red and magenta lines are satellite-to-pixel vector when topography is considered for visible (red) and shaded (magenta) points. The subscripts "s" indicate the projection of each point on the ground.

on the soil type and $\varepsilon_{\mathrm{S}}$ model. The dielectric constant of all soil types except clay is lower when the model discussed in [15] was used than when the model in [16] was used.

\section{Variations Due to Vegetation Attenuation in the High-Resolution Maps}

The availability of the MCSC has made it possible to calculate opacity directly from the VWC using the study in [13].

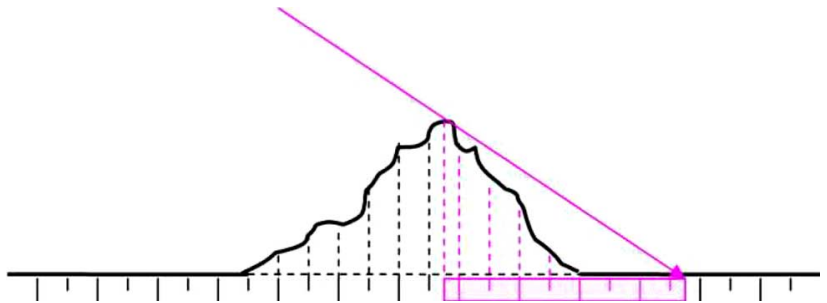

Fig. 7. Estimation of the pixels affected by shadowing (magenta area) for each SMOS footprint once the topography has been included in the simulation.

The vegetation attenuation simulated in the previous SEPS release is shown in Fig. 4 (left). There are some areas in the Pyrenees that have no value (black) because they are covered by snow. Other areas have values near $0 \mathrm{~dB}$, which means that there is no attenuation due to vegetation because there is no canopy. Fig. 4 (right) shows the difference in the vegetation attenuation between the high- and the low-resolution versions of SEPS. Large differences between the two images are observed, particularly in the northeastern areas, where there are many agricultural fields and natural parks. This area with different land cover types could be employed to test the 

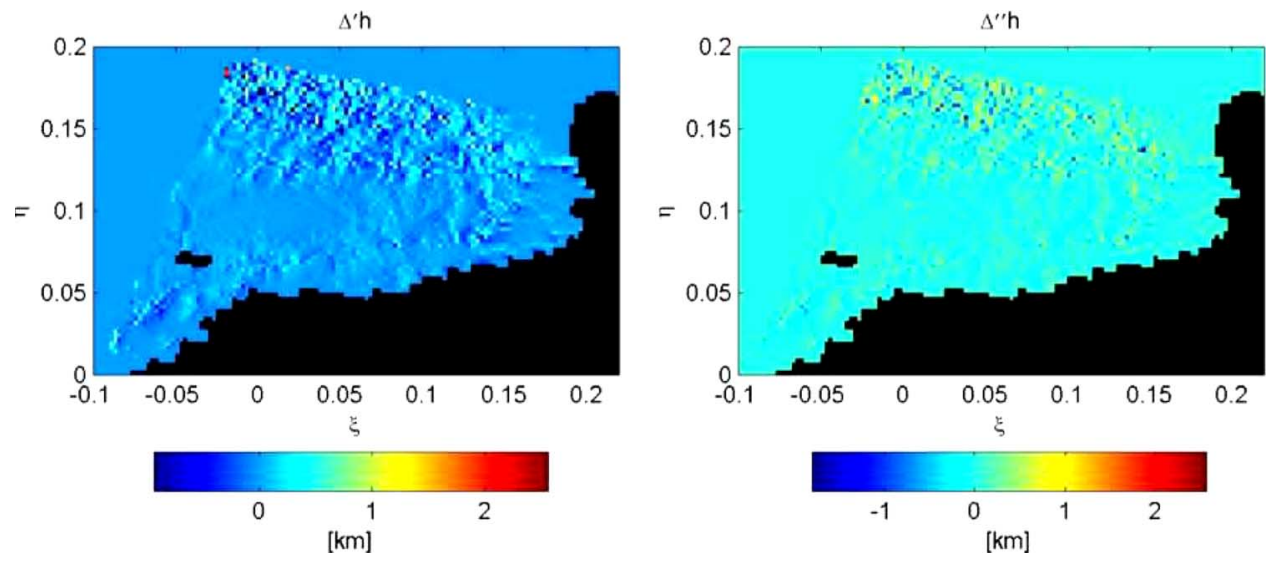

Fig. 8. (Left) Variation of each pixel height after the DEM is taken into account. (Right) Variation of each pixel height when both shadowing and topography are considered. The simulation corresponds to an ascending SMOS orbit.

performance of soil moisture algorithms when a mixed pixel is involved.

\section{Contribution of the Atmosphere}

Three atmospheric contributions to the brightness temperature are considered in the radiative transfer model: the upwelling $T_{\mathrm{up}}$ and downwelling $T_{\mathrm{dn}}$ temperatures, and the attenuation $L_{\text {atm }}$ between the surface and the satellite. These values have been computed using Liebe's 1989 model [17], which is sufficiently accurate at L-band and takes into account the atmospheric path length and the pixel height $h$. The attenuation of the measured emission due to the atmosphere, and the up and downwelling temperatures are thus computed for every image pixel. Results obtained after simulation using SEPS for the vertical polarization are shown in Fig. 5. Horizontal polarization has not been included because the results were the same.

The attenuation due to the atmosphere decreases as the pixel height increases because the total atmospheric path length to be considered decreases (see Fig. 5). The maximum variation of $L_{\text {atm }}$ due to topography $\Delta L_{\mathrm{atm}}$ is $0.03 \mathrm{~dB}$, as shown in Fig. 5(a). Pyrenees (north of Catalonia) and other mountainous regions have a negative $L_{\mathrm{atm}}$, which means that $L_{\mathrm{atm}}$ is lower than that of the flat land. $\Delta L_{\text {atm }}$ values near zero correspond to areas near the coastline or interior plateaus. The up- and downwelling temperatures also decrease up to $1 \mathrm{~K}$ as the pixel height increases, as can be seen in Fig. 5(b).

\section{E. Effects of the Topography}

1) Shadowing: Previous SEPS releases assumed that all the points on Earth were on the WGS-84 ellipsoid, which means that their mean sea level height was not taken into account. All the points on the ellipsoidal Earth had a correspondence between the pixel coordinates in the $\operatorname{SMOS}(\xi, \eta)$ reference frame and the coordinates in (latitude, longitude). Now that the DEM has been considered in the brightness temperature computation, not all the points in the SMOS FOV are in the same plane, and thus, some of them can be shaded by others.

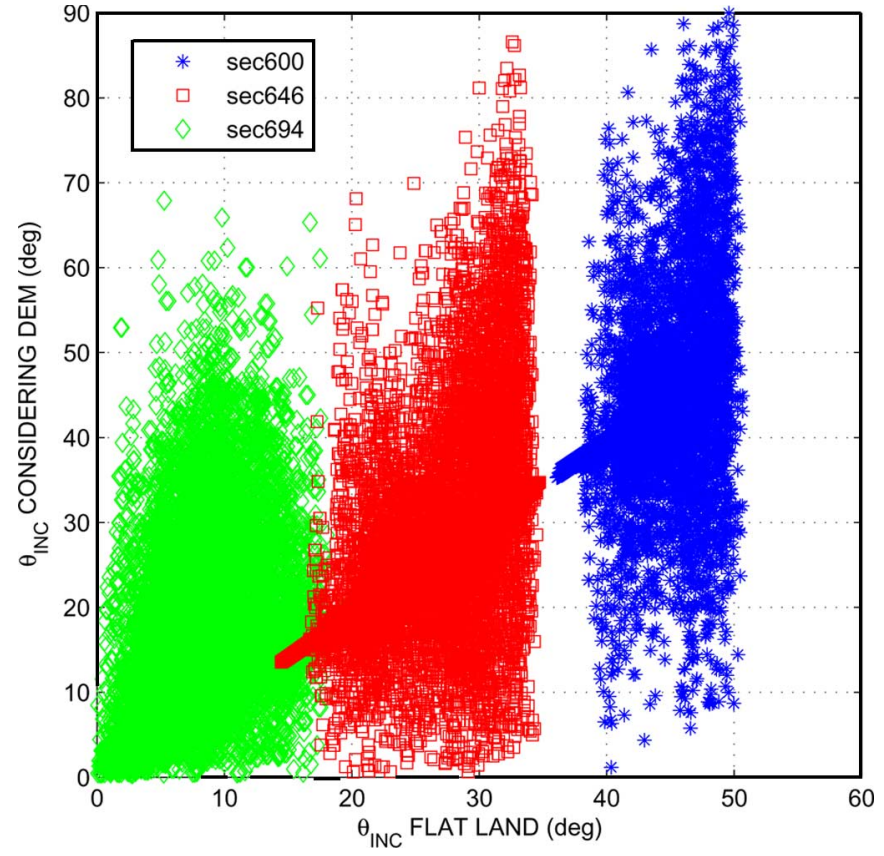

Fig. 9. Maximum variations of local incidence angle due to topography. Icons stand for the instants in time: ${ }^{*}$ Catalonia is entering the FOV, $\square$ Catalonia is in the middle of the FOV, and $\diamond$ Catalonia is almost outside the FOV.

SEPS has been modified so that the brightness temperature values are computed for all the observed points, and then, a mask is applied to modify the points affected by shadowing. The problem now is that not all the pixels are at sea level, and thus, their projection on the ground could differ from the (latitude, longitude) coordinates estimated in the ellipsoidal Earth scenario. The solution to this problem has been implemented as follows.

1) A height value is assigned to every pixel in the FOV using the DEMC.

2) Two sets of vectors are created.

a) The first one contains all the satellite-to-pixel vectors when all ground pixels are assumed to be at sea level (blue lines in Fig. 6). 


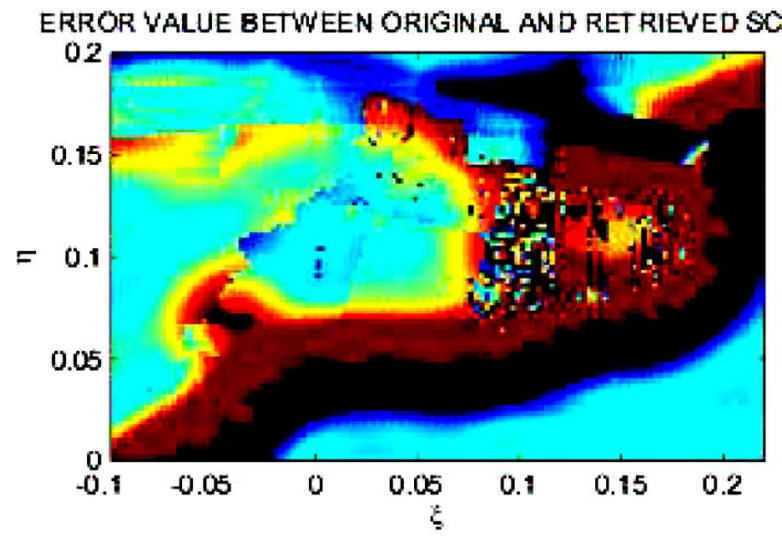

(a)
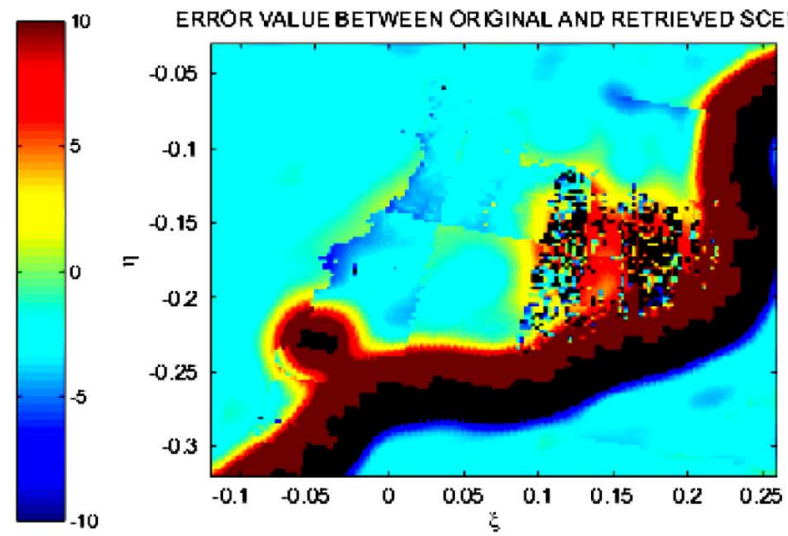

(b)

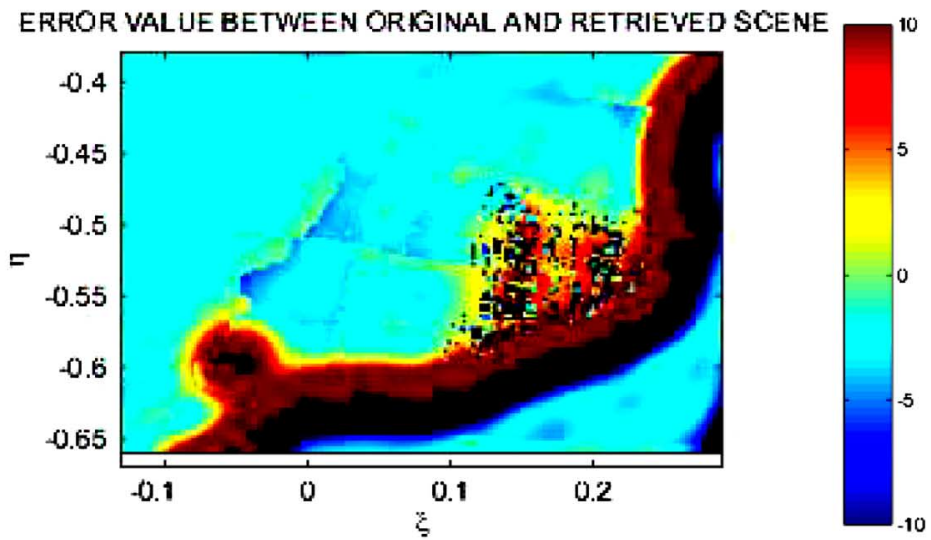

(c)

Fig. 10. Error computed as the difference between the original high-resolution TB images and the retrieved ones in the SEPS. (a) Instant 1, Catalonia enters in the FOV. (b) Instant 2, Catalonia is in the middle of the FOV. (c) Instant 3, Catalonia exits the FOV.

b) The second one contains all the satellite-to-pixel vectors when the DEMC is included (red lines in Fig. 6).

3) The vectors in the first set are substituted by the nearest vector in the second set if they have a lower norm. This condition is represented in Fig. 6, where the point 1s would be substituted by the point 2 .

4) Based on these vectors, a mask is computed to isolate the shadowed points.

a) The relative maxima in the SMOS FOV are computed for the satellite trajectory and are considered to be capable of shading other pixels.

b) The relative maxima are projected to reach the ground, as shown in Fig. 7. All the pixels between the local maximum pixel and its projection to the ground are considered shadowed.

5) To correct the shadowed pixels, the same two sets defined in step 2) are used, but with the condition that a shadowed pixel can be replaced only by an unshadowed one.

Simulation results of these issues are shown in Fig. 8. The left image shows the difference between the actual height of the pixel (DEM value, which would correspond to an observation from the satellite at nadir) and the height of the pixel as seen from SMOS depending on the observation angle [step 3) of the algorithm], and the right image shows the final height variation, after shadowing has been considered [step 5)]. The simulation corresponds to an ascending orbit; therefore, pixels with a positive increment correspond to shadowed pixels. A mountainous pattern can be seen in the Pyrenees zone.

2) Variations of the Local Incidence Angle: Once the digital elevation model has been taken into account, changes in the local incidence angle must be assessed. Based on the DEMC, a surface is constructed, and the normal vector for every $30 \times$ $30 \mathrm{~m}$ pixel in the DEMC is computed. The actual local incidence angle $\theta_{\text {inc }}^{\prime}$ is then calculated from the scalar product of the pixel-to-satellite unit vector and the normal vector to the surface in the pixel. $\theta_{\text {inc }}^{\prime}$ is the value to be used in the estimation of land radiometric emission from the existing models. Fig. 9 shows some simulation results for three instants in time, which are represented by different icons: * Catalonia is entering the FOV, $\square$ Catalonia is in the middle of the FOV, and $\diamond$ Catalonia is almost outside the FOV. The local incidence angle variation due to topography can be up to $55^{\circ}$, which could lead to important variations in the results from the land emission models.

\section{F. Simulation Results}

In the preparation of suitable calibration/validation sites for SMOS, it is very important to know the instrument 
performance in terms of spatial and radiometric resolutions. These two parameters and the homogeneity of the region will ultimately limit the capability to compare single-point measurements to satellite measurements. SMOS average spatial resolution is about $50 \mathrm{~km}$ (in fact, it varies from about $30 \mathrm{~km}$ to more than $60 \mathrm{~km}$ depending on the incidence angle), and the radiometric sensitivity at boresight is about $2-3 \mathrm{~K}$, depending on the target. This limits the selection of calibration/validation sites to very large and homogeneous regions. A number of sites have been proposed, and among them is the Lleida Plateau in Spain. In this paper, the validity of that selection is shown by demonstrating the low error that may be expected from the single-point measurements versus SMOS measurement.

Simulation results using $800 \times 800$ pixels brightness temperature images in SEPS have been analyzed. Three snapshots of a simulated SMOS orbit, which correspond to the instant at which Catalonia enters SMOS FOV, is in the middle of the FOV, and exits the FOV, respectively, have been selected in this paper. Fig. 10 shows the error computed as the difference between the original high-resolution TB images and the retrieved ones (inherently with lower spatial resolution). Coastline effects are very noticeable in the whole image. There is a region in which the error is very small, nearly zero, while in other regions, the difference can be higher than $10 \mathrm{~K}$ due to land use mosaic and variety of vegetation species. In the Pyrenees, the difference can be a few Kelvin, which could be acceptable for some applications. The region with the lowest error occupies about $1 \times 2$ SMOS pixels (that is, about $50 \times 100 \mathrm{~km}$ ) and can be relatively safely used as a calibration/validation site. Best results are obtained for the second instant in time, when the area of interest is in the middle of the FOV and there are more observations of each pixel.

\section{CONCLUSION}

The new high-resolution brightness temperature $\left(T_{\mathrm{B}}\right)$ generator of Catalonia (northeast Spain) included in the SEPS has been presented in this paper. A land cover and a digital elevation map of the Region have been included in the simulator to estimate the effects of shadowing, atmosphere, and variations in the local incidence angle due to mixed pixels and topography. Results have been compared to $T_{\mathrm{B}}$ values that are computed under the assumption of an ellipsoidal Earth, when all the points are at sea level. Large differences are observed in the attenuation due to vegetation when different canopies are considered. As expected, the attenuation due to the atmosphere decreases as the pixel height increases. This effect also occurs with the up- and downwelling temperatures. Variations in the local incidence angle can be up to $55^{\circ}$, and thus, there could be important changes in the simulated brightness temperature. SEPS and the new high-resolution brightness temperature generator can be used to test potential SMOS calibration/validation sites by checking the homogeneity of the input parameters as compared to the SMOS spatial resolution. Simulation results show that the Lleida Plateu, about $50 \times 100 \mathrm{~km}$ in extent, could be a suitable place for SMOS calibration/validation, among other regions in
Spain that are well equipped and are homogeneous on the scale of the SMOS pixel size.

\section{ACKNOWLEDGMENT}

The authors would like to thank J. Á. Buriel (Centre de Recerca Ecològica i Aplicacions Forestals), who provided the land cover map of Catalonia, and the anonymous reviewers whose useful comments improved this manuscript.

\section{REFERENCES}

[1] A. Camps, I. Corbella, M. Vall-llossera, N. Duffo, F. Marcos, F. MartínezFadrique, and M. Greiner, "The SMOS end-to-end performance simulator: Description and scientific applications," in Proc. IGARSS, Toulouse, France, Jul. 2003, vol. 1, pp. 13-15.

[2] I. Corbella, A. Camps, M. Zapata, F. Marcos, F. Martínez, F. Torres, M. Vall-llossera, N. Duffo, and J. Bará, "End-to-end simulator of two-dimensional interferometric radiometry," Radio Sci., vol. 38, no. 3, 8058, Jun. 2003. DOI 10.1029/2002RS002665.

[3] Software Copyright @ICC1996-2006 NIF Q0840005-C, Digital Elevation Map of Catalonia. Resolution $30 \times 30 \mathrm{~m}$, Institut Cartogràfic de Catalunya (ICC). [Online]. Available: http://www.icc.es

[4] in Land Cover Map of Catalonia by the Centre de Recerca Ecològia $i$ Aplicacions Forestals (CREAF). Sponsored by the Departament de Medi Ambient i Habitatge de la Generalitat de Catalunya. [Online]. Available: http://www.creaf.uab.es/MCSC

[5] F. T. Ulaby, R. K. Moore, and A. K. Fung, Microwave Remote Sensing (Active and Passive), vol. 2. Reading, MA: Addison-Wesley, 1986.

[6] P. Ferrazzoli, L. Guerriero, and J. P. Wigneron, "Simulating L-band emission of forests in view of future satellite applications," IEEE Trans. Geosci. Remote Sens., vol. 40, no. 12, pp. 2700-2708, Dec. 2002.

[7] V. F. Krapivin, A. M. Shutko, A. A. Chukhlantsev, and S. P. Golovachev, "Vegetation microwave monitoring using GIMS-based method," in Proc. URSI, Gandia, Spain, Sep. 2005. Cap. 3 No. 8.

[8] A. A. Van de Griend and J. P. Wigneron, "On the measurement of microwave vegetation properties: Some guidelines for a protocol," IEEE Trans. Geosci. Remote Sens., vol. 42, no. 10, pp. 2277-2289, Oct. 2004.

[9] J. P. Wigneron, M. Parde, P. Waldteufel, A. Chanzy, Y. Kerr, S. Schmidl, and N. Skou, "Characterizing the dependence of vegetation model parameters on crop structure, incidence angle and polarization at L-band," IEEE Trans. Geosci. Remote Sens., vol. 42, no. 2, pp. 416-425, Feb. 2004.

[10] A. Monerris, M. Cardona, M. Vall-llossera, A. Camps, R. Sabia, R. Villarino, E. Álvarez, and S. Sosa, "Soil moisture retrieval errors using L-band radiometry induced by the soil type variability," in Proc. IGARSS, Seoul, Korea, Jul. 2005, vol. 2, pp. 1123-1126.

[11] M. Vall-llossera, M. Cardona, S. Blanch, A. Camps, A. Monerris, I. Corbella, F. Torres, and N. Duffo, "L-band dielectric properties of different soil types collected during the MOUSE 2004 field experiment," in Proc. IGARSS, Seoul, Korea, Jul. 25-29, 2005, vol. 2, pp. 1109-1112.

[12] M. Gentile, "Analisi statistica di propagazione di campo elettromagnetico in ambito urbano," M.S. thesis, Univ. Pisa, Pisa, Italy, 2003.

[13] A. A. Van de Griend and J. P. Wigneron, "The B-factor as a function of frequency and canopy type at H-polarization," IEEE Trans. Geosci. Remote Sens., vol. 42, no. 4, pp. 786-794, Apr. 2004.

[14] J. P. Claassen and A. K. Fung, "The recovery of polarized apparent temperature distributions of flat scenes from antenna temperature measurements," IEEE Trans. Antennas Propag., vol. AP-22, no. 3, pp. 433-442, May 1974.

[15] J. R. Wang and T. J. Schmugge, "An empirical model for the complex dielectric permittivity of soils as a function of water content," IEEE Trans. Geosci. Remote Sens., vol. GRS-18, no. 4, pp. 288-295, Oct. 1980.

[16] M. C. Dobson, F. T. Ulaby, M. T. Hallikainen, and M. A. El-Rayes, "Microwave dielectric behaviour of wet soils, Part II: Dielectric mixing models," IEEE Trans. Geosci. Remote Sens., vol. GRS-23, no. 1, pp. 3546, Jan. 1985

[17] H. J. Liebe, "MPM-An atmospheric millimeter-wave propagation model," Int. J. Infrared Millim. Waves, vol. 10, no. 6, pp. 631-650, Jun. 1989. 


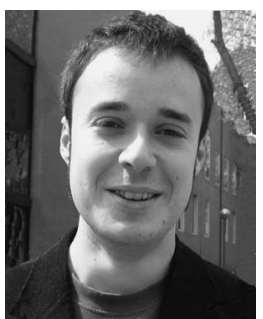

Marco Talone (S'06) was born in Valmontone, Italy, in 1981. He received the degrees in telecommunication engineering from Tor Vergata University, Rome, Italy, in 2003 and 2006, respectively, and worked on his master's thesis at the Department Teoria del Senyal i Comunicacions (TSC), Universitat Politècnica de Catalunya, Barcelona, Spain, in 2005.

He joined the TSC Group as a Ph.D. student. He is currently with the Remote Sensing Laboratory, Department Teoria del Senyal i Comunicacions, Universitat Politècnica de Catalunya, Barcelona, Spain. His research interests are microwave radiometry and sea surface salinity retrieval methods.

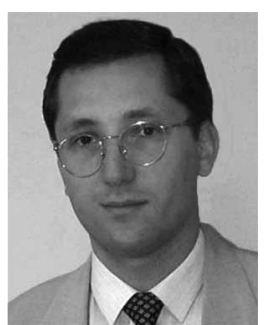

Adriano Camps (S'91-A'97-M'00-SM'03) was born in Barcelona, Spain, in 1969. He received the B.S. and Ph.D. degrees in telecommunications engineering from the Universitat Politècnica de Catalunya (UPC), Barcelona, Spain, in 1992 and 1996, respectively.

From 1991 to 1992, he was with the ENS des Télécommunications de Bretagne, Bretagne, France, with an Erasmus Fellowship. He joined the Electromagnetics and Photonics Engineering Group of the Remote Sensing Laboratory, Department Teoria del Senyal i Comunicacions, Universitat Politècnica de Catalunya, in 1993 as an Assistant Professor, where he has been an Associate Professor since 1997. He was on a sabbatical leave at the Microwave Remote Sensing Laboratory, University of Massachusetts, Amherst, in 1999. He has performed numerous studies within the frame of the European Space Agency's SMOS Earth Explorer Mission. He is an Associate Editor of Radio Science. His research interests include microwave remote sensing, with special emphasis on microwave radiometry by aperture synthesis techniques.

Dr. Camps is the President-Founder of the IEEE Geoscience and Remote Sensing Society Chapter, Spain, and was the Chair of $\mu \mathrm{Cal}$ in 2001. He is the Editor of the IEEE Geoscience and Remote Sensing Newsletter. He received the Second National Award of University Studies in 1993, the INDRA Award of the Spanish Association of Telecommunication Engineering for the best Ph.D. dissertation in 1997, the Extraordinary Ph.D. Award from the Universitat Politècnica de Catalunya in 1999, the First Duran Farell Award and the Ciudad de Barcelona Award, both for Technology Transfer, in 2000 and 2001, respectively, and the Research Distinction of the Generalitat de Catalunya for his contributions on microwave passive remote sensing in 2002 . He is also the recipient of "Premi Nacional de Telecomunicacions 2003," "Premi Salv i Campillo 2004," and the "2004 European Young Investigator Award."

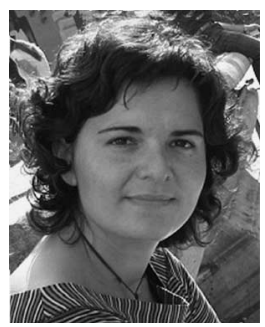

Alessandra Monerris (S'04) received the degree in telecommunication engineering from the Universitat Politècnica de València (UPV), Valencia, Spain, in December 2001. She is currently working toward the Ph.D. degree at the Universitat Politècnica de Catalunya (UPC), Barcelona, Spain, with an FPU grant from the Spanish Ministerio de Educacién y Ciencia.

She was with the Microwave Applications Group, UPV, developing numerical methods for the electromagnetic analysis of waveguide-based devices. Since 2002, she has been with the Remote Sensing Laboratory, Department Teoria del Senyal i Comunicacions, UPC. She has been involved in many field experiments sponsored in the frame of the SMOS mission: FROG 2003, REFLEX 2003 and 2006, MOUSE 2004, T-REX 2004 and 2006, and TuRTLE 2006. Her research interests include surface-soil moisture retrieval algorithms from brightness temperature measurements.

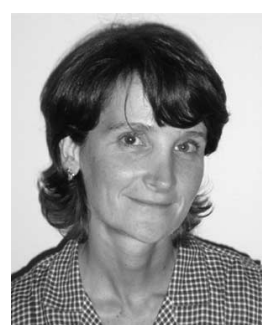

Mercè Vall-llossera (M'99) received the M.Sc. and $\mathrm{Ph} . \mathrm{D}$. degrees in telecommunication engineering from the Universitat Politècnica de Catalunya (UPC), Barcelona, Spain, in 1990 and 1994, respectively.

From 1990 to 1997, she was with the Remote Sensing Laboratory Department Teoria del Senyal i Comunicacions, UPC, as an Assistant Professor, where she has been an Associate Professor since 1997. She spent a sabbatical year in Montreal with the scholarship of the "Programme Québécois de Bourses d'excellence" 1996-1997: "Stages de Formation postdoctorale au Québec pour jeunes diplômés étrangers." Her research interests include numerical methods in electromagnetics, microwave radiometry, antenna analysis, and design. Her current research is mainly related to the study of numerical methods applied to the sea surface emissivity and their characterization at the L-band and the MIRAS/SMOS project.

Dr. Vall-1lossera and the other members of the Radiometry Group at UPC received the "Primer Premio Duran Farell de Investigación Tecnológica" in 2000, the "Primer Premio Ciutat de Barcelona de Investigación Tecnológica" in 2001, and the Ninth Edition of the Salvà i Campillo in February 2004.

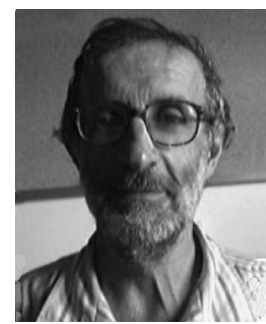

Paolo Ferrazzoli (M'94) received the degree from the University of Rome "La Sapienza," Rome, Italy, in 1972.

In 1974, he joined Telespazio s.p.a., where he was mainly active in the fields of antennas, slantpath propagation, and advanced satellite telecommunication systems. In 1984, he joined Tor Vergata University, Rome, where he is currently working and teaching microwaves and propagation in the Dipartimento di Ingegneria Informatica, Sistemi e Produzione. His research is focused on microwave remote sensing of vegetated terrains, with particular emphasis on electromagnetic modeling. He has been involved in international experimental remote sensing campaigns such as AGRISAR, AGRISCATT, MAESTRO-1, MACEurope, and SIR-C/X-SAR. He has participated in the coordinating team of the ERA-ORA Project, which was funded by EEC, establishing an assemblage among several European researchers working in radar applications.

Mr. Ferrazzoli is a member of the Science Advisory Group of the ESA SMOS Project.

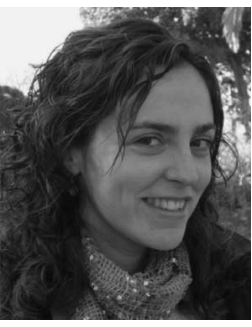

María Piles (S'05) received the degree in telecommunication engineering from the Universitat Politècnica de València, Valencia, Spain, in September 2005. She is currently working toward the Ph.D. degree at the Universitat Politècnica de Catalunya (UPC), Barcelona, Spain, with an FPU grant from the Spanish Ministerio de Educación y Ciencia.

During August 2004 to June 2005, she received an Erasmus fellowship to study at the Lund Institute of Technology, Lund, Sweden. Since October 2005, she has been with the Remote Sensing Laboratory, Department Teoria del Senyal i Comunicacions, UPC. She has been involved in the development of pixel disaggregation techniques for image reconstruction and improvements of the spatial resolution in the ESA's SMOS mission. Her research interests include remote sensing for earth observation, data fusion, and image enhancement and restoration. 